\title{
Estudo da anatomia descritiva e topográfica do músculo digástrico em primatas (Cebus apella, Linnaeus, 1766)
}

Jussara Rocha FERREIRA ${ }^{\text {; }}$ Norival PINTO JÚNIOR² ; Daissuke KAJITA²; Denise Soares de CIRQUEIRA ${ }^{3}$; Douglas José NOGUEIRA ${ }^{1}$

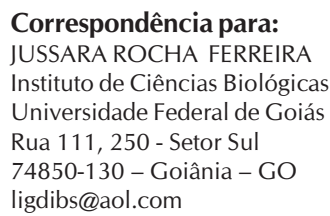

Recebido para publicação: 29/05/2003 Aprovado para publicação: 15/03/2005

\author{
1- Instituto de Ciências Biológicas da Universidade Federal de Goiás, \\ Goiânia - GO \\ 2- Médico, auxiliar \\ 3- Enfermeira, auxiliar
}

Resumo

Neste estudo utilizamos 18 (dezoito) cabeças de macacos prego (Cebus apella) cedidos pelo Departamento de Cirurgia da Faculdade de Medicina Veterinária e Zootecnia da Universidade de São Paulo, e provenientes do Zoológico da cidade de São Paulo, vindos a óbito naturalmente. O método incluiu técnica de mesoscopia de luz, sendo a rotina técnica: canulação da aorta no sentido cranial; perfusão com água morna $\left(40^{\circ} \mathrm{C}\right)$; injeção do sistema arterial com solução de látex (Neoprene 450) corado (sulvinil corante), fixação e conservação em solução aquosa de formol a 10\%. Foram dissecados trinta e seis antímeros. O músculo digástrico, composto por dois ventres (rostral e caudal) unidos por um tendão intermediário, inseriu-se na linha paramediana da mandíbula, indo $\mathrm{da}$ borda ventral incisiva à borda ventral molar (ventre rostral). $\mathrm{O}$ modo de origem, trajeto e a direção das fibras apresentou três arranjos: um com ventres planos e tendão fusiforme (55,5\%); um com ventre plano, fibras ancoradas caudolateralmente na borda ventral mandibular e tendão fusiforme (38,9\%); e um ventre fusiforme com tendão fusiforme. $\mathrm{O}$ ventre caudal relacionou-se com o ventre e o tendão do músculo estilo-hióideo: cruzando-o ventralmente $(22,2 \%)$ ou dorsalmente $(2,7 \%)$; cruzando o tendão intermediário: ventralmente $(35,9 \%)$ ou dorsalmente $(33,2 \%)$. O músculo digástrico (ventre rostral) é plano no Cebus apella (94,4\%) tem ampla inserção óssea na borda ventral mandibular e o tendão intermediário apoia-se na fáscia cervical em expansão lateral até atingir o osso compondo um duplo ponto de apoio $(38,9 \%)$.

\section{Introdução}

A Revolução Verde fez a agricultura e a pecuária avançar pelas terras ácidas, uma das últimas fronteiras de expansão agro-pastoril do planeta Terra. O cerrado na Região CentroOeste do Brasil encontra-se entre tais terras. A partir notadamente da década de 70, diversos centros de pesquisa desenvolveram plantas cultiváveis nestas terras e, na seqüência houve a derrubada das matas, savanas e campos, para ocupação agro-pastoril. Produzir nas terras aráveis do mundo impõe-nos desafios formidáveis. A ciência precisa ser, ao mesmo tempo, preservacionista e suprir a fome de uma população estimada em nove bilhões de pessoas antes dos meados deste século XXI. Estudos sobre a morfologia de animais do cerrado, auxiliam na difusão do conhecimento destes animais, por exemplo, o primata Cebus apella, que vive neste bioma e que naturalmente teve em grande parte seu habitat natural modificado em função da ocupação da terra para produzir alimentos. Estudos científicos 
certamente contribuirão de maneira harmoniosa para a preservação das espécies $\mathrm{X}$ ocupação humana dos biomas. Tendo nas nossas matas o maior estoque destes animais ainda vivendo em condições naturais, entendese que este significativo patrimônio genético precisa ser pesquisado em todos os seus aspectos.

Entre os primatas neotropicais, existe um grupo de macacos que, respeitados os conceitos de espécie e subespécie (HERNANDES CAMACHO; COOPER, 1976 apud BROWN; COLILLAS², 1983, p. 306), foram classificados e são conhecidos como do gênero Cebus; e dentre estes encontrase o Cebus apella. Historicamente, os primatas não humanos tem sido descritos usando-se o modelo humano como padrão, para as suas características morfológicas. Neste último século os novos paradigmas das ciências levam-nos a repensar e reordenar o rumo das pesquisas, respeitando-se a opção evolutiva de cada espécie na estrutura e plasticidade do seu biótipo ${ }^{3}$.

Em relação aos músculos suprahióideos, os tratados clássicos descrevem, em humanos, o músculo digástrico com dois ventres fusiformes unidos por um tendão intermediário, que pode ou não perfurar o músculo estilo-hióideo, e ancorar-se no osso hióide ${ }^{4,5,6}$. Em macaco rhesus foi descrita a relação da glândula submandibular com o músculo digástrico ${ }^{7}$ e descreveu-se o nervo acessório passando medialmente a este. Outros relatos ${ }^{8}$ indicam relações topográficas do músculo com a artéria carótida interna ${ }^{8}$, tireóidea superior e tronco tíreo-linguo-facial. Este trabalho teve o propósito de verificar características morfológicas do músculo digástrico no Cebus apella, estabelecendo comparações com outros primatas.

\section{Materiais e Métodos}

Utilizamos 18 (dezoito) cabeças de macacos prego (Cebus apella) cedidos pelo Departamento de Cirurgia da Faculdade de Medicina Veterinária e Zootecnia da Universidade de São Paulo, e provenientes do Zoológico da cidade de São Paulo, vindos a óbito naturalmente. $\mathrm{O}$ método incluiu técnica de mesoscopia de luz (40 aumentos), sendo a rotina técnica: canulação da aorta no sentido cranial; perfusão com água morna $\left(40^{\circ} \mathrm{C}\right)$; injeção do sistema arterial com solução de látex (Neoprene 450) corado (sulvinil corante), fixação e conservação em solução aquosa de formol a 10\%. Foram dissecados trinta e seis antímeros, rebatendo a pele da face e do pescoço e o músculo platisma, evidenciando a região ocupada pelos ventres do músculo digástrico e o seu tendão intermediário. Foram esquematizados as relações de cada ventre. A terminologia utilizada foi baseada na nomenclatura oficial $^{9,10}$. Empregou-se os termos músculo digástrico, ventre rostral, ventre caudal; tendão intermediário e corpo da mandíbula (parte incisiva, parte molar e borda ventral).

\section{Resultados}

Analisaram-se nesta pesquisa o modo de origem e a inserção do músculo digástrico, ventres caudal e rostral e tendão intermediário com suas respectivas relações topográficas, no macaco prego. Após o rebatimento da pele da região inferior do pescoço apresentou-se uma fina camada muscular, o músculo platisma (Figura 1 B), que recobria o ventre rostral do músculo digástrico. O músculo digástrico é composto de dois ventre carnosos, um plano (rostral) e um fusiforme (caudal) unidos por um tendão intermediário comum. O ventre rostral insere-se no corpo da mandíbula na margem ventral incisiva estendendo-se até a margem ventral da parte molar do osso (Figura $1 \mathrm{~A}$, C, D), alcançando a margem anterior da inserção ventral do músculo masseter. Estende-se ventro-caudalmente e nos dois antímeros, os ventres encontram-se em justaposição na linha mediana unidos por estruturas aponeuróticas (Figura 1 C ). As fibras se direcionam caudo-lateralmente formando um tendão convexo de $\mathrm{U}$ que vai compor o segmento rostral do tendão intermediário (Figura 1 C). 


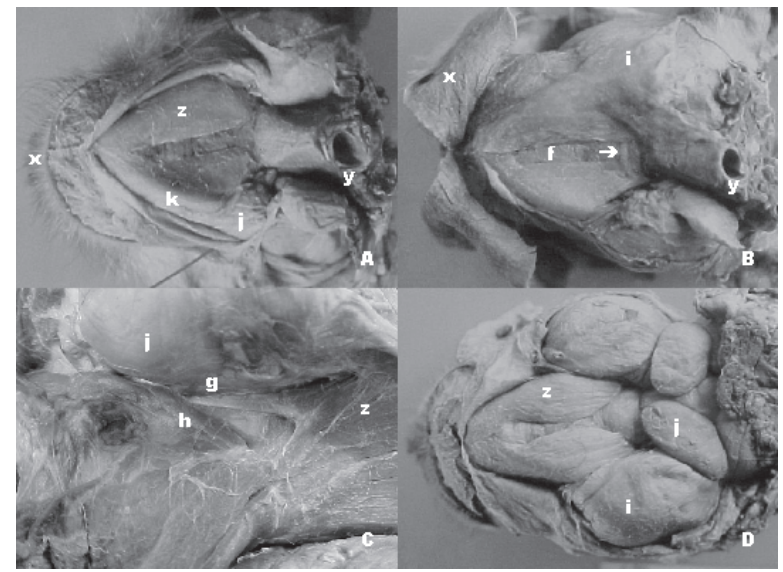

Figura 1 - Fotografia da vista ventral da cabeça e pescoço do macaco prego (Cebus apella) evidenciando: pele (x), traquéia (y), fáscia cervical e músculo platisma (w), ventre rostral do músculo digástrico (z), osso hióide (Ô), músculo milo-hióideo (f), tendão intermediário do músculo digástrico (g), músculo estilo-hióideo (h), músculo masseter (i), Glândula salivar sub-mandibular (j), ramo da mandíbula (k)

Tabela 1 - Inserção rostral e caudal do ventre rostral do músculo digástrico, no primata Cebus apella (Linnaeus, 1766) com indicação da direção das fibras em relação às inserções rostrais e caudais em função da quantidade de espécimes analisadas. Goiânia, 2002

\begin{tabular}{lcc}
\hline $\begin{array}{l}\text { Representação esquemática do ventre rostral do músculo digátrico (a), } \\
\text { direção das fibras em relação à inserção rostral (b) e à inserção caudal } \\
\text { (c, tendão intermediário) }\end{array}$ & $\begin{array}{c}\text { Espécimalizados } \\
\%\end{array}$ \\
\hline & 20 & $55,5 \%$ \\
& 14 & $38,9 \%$ \\
$5,5 \%$ & 02 & $100 \%$ \\
\hline Total & 36 & 100 \\
\hline
\end{tabular}

Fonte: dados de pesquisa, trabalhados pelos autores Departamento de Morfologia ICB/UFG

O ventre caudal do músculo digástrico apresentou-se fusiforme, longo, dirigindo-se obliquamente em sentido caudorostral tendo inserção óssea no processo paracondilar do osso temporal parcialmente encoberto pelas inserções dos músculos esternocleidomastóideo e esplênio da cabeça. Em toda a sua extensão encontrou-se em íntima relação com o músculo estílo-hióide. Nas proximidades do osso hióide, o ventre continuou-se por um tendão roliço, cuja extremidade rostral confundiu-se com as fibras do tendão do ventre rostral. $\mathrm{O}$ tendão em arco anteriormente mencionado estava preso à borda anteromedial do osso hióide por espessa membrana aponeurótica (Figura $1 \mathrm{C}, \mathrm{D})$.

Os dois ventres assim constituídos formaram um ângulo obtuso com a base da mandíbula e demarcaram um triângulo submandibular, juntamente com os músculos milo-hióideo e o nervo hipoglosso, ocupado em grande parte pela glândula submandibular muito expressiva neste macaco.

O ventre rostral encontrou-se coberto pelo músculo platisma e apoiou-se dorsalmente ao músculo milo-hióideo, separados pelas respectivas fáscias musculares contribuindo na formação do assoalho bucal. A partir da borda ventral do corpo da mandíbula, parte incisiva, as fibras musculares direcionam-se ao osso hióide, configurando três formas de ventres, arranjados em direção ao tendão intermediário, demonstrados na tabela 1 . O comprimento do ventre rostral na maioria dos espécimes correspondeu ao tamanho do corpo da mandíbula podendo ser mais (Figura 1 A) ou menos (Figura 1 B) hipertrofiado. A largura dos ventres em cada antímero analisado, apresentou três variações de forma ocupando a região triangular 
(submentoniana), delimitada anterolateralmente pela mandíbula e posteromedialmente pelo osso hióide, reforçando a camada muscular do assoalho da cavidade oral e base da língua. O tendão intermediário na região caudal do ventre rostral se alargou e suas fibras encontravamse ancoradas ao corpo e ao corno do osso hióide através de estruturas aponeuróticas provenientes da fáscia cervical e do músculo milo-hióideo, compondo diferentes arranjos (Figura 1 B e Tabela 1).

O ventre rostral apresentou a topografia a seguir: relacionou-se inferiormente com a porção submandibular do músculo platisma (100\%); superiormente na região submandibular com o músculo milo-hióideo (100\%); na borda pósterolateral do ventre rostral, a artéria e a veia facial correram paralelas ao ventre muscular, até atingir a borda ventral da mandíbula bilateralmente $(11,1 \%)$; com a glândula submandibular caudo-lateralmente nos dois antímeros $(33,3 \%)$, à direita $(11,1 \%)$ e à esquerda $(2,7 \%)$; com o músculo masseter através da porção caudo-lateral do ventre rostral $(22,2 \%)$, somente no antímero direito (2,7\%); com linfonodos submandibulares em situação ventral ao músculo bilateralmente $(55,5 \%)$, e em situação ventral ao tendão intermediário nos dois antímeros (16,6\%). A porção posterior do ventre rostral estendeu-se até o corpo do osso hióide à direita e a porção medial do ventre caudal dirigiu-se ao corpo do osso hióide onde se inseriu $(2,7)$; na observação 6 bilateralmente a porção rostral do músculo estilo-hióideo insinuou-se, de lateral para medial dorsalmente à porção posterior do ventre rostral do músculo digástrico ( $5,5 \%)$.

As relações topográficas do tendão intermediário e do ventre caudal do músculo digástrico são descritas a seguir: a alça formada pelo nervo hipoglosso encontrouse mediamente ao ventre caudal $(100 \%)$; o terço do ventre caudal relacionou-se com o feixe vásculo-nervoso do pescoço (100\%); o músculo estilo-hióideo apresentou trajeto paralelo ao ventre caudal do músculo digástrico e seu tendão intermediário, cruzando-os em diferentes arranjos (Tabela 2). Em 4 casos bilateralmente $(22,2 \%)$ o ventre do músculo estilo-hióideo cruzou a porção rostral do ventre caudal de lateral para medial, ocupando posição ventral a este. Em um caso bilateralmente $(5,5 \%)$ o ventre do estilo-hióideo ocupou a posição cranial no sentido do cruzamento descrito acima. Em um único caso, apenas à esquerda o estilohióideo ocupava posição cranial no referido cruzamento $(5,5 \%)$. Nos demais casos o músculo estilo-hióideo cruzou o tendão intermediário do músculo digástrico de diferentes modos descritos em seguida.

Tabela 2 - Relação topográfica entre o músculo digástrico e o músculo estilo-hióideo do primata Cebus apella (Linneaus, 1766) em função dos ventres nos antímeros e quantidade de espécimes. Goiânia, 2002

\begin{tabular}{|c|c|c|c|c|c|}
\hline \multirow{12}{*}{$\begin{array}{l}\text { Representação esquemática do músculo } \\
\text { digástrico, ventre caudal (a) tendão } \\
\text { intermediário (b) e ventre rostral } \\
\text { ao ventre do músculo estilo-hióideo }(\mathrm{d}) \text {. }\end{array}$} & \multicolumn{4}{|c|}{ Ventres } & \multirow{3}{*}{$\%$} \\
\hline & \multicolumn{2}{|c|}{ Antimeros (n) } & \multicolumn{2}{|c|}{ Antimeros (n) } & \\
\hline & Direito & Esquerdo & $\begin{array}{c}\text { Direit } \\
0\end{array}$ & Esquerdo & \\
\hline & 4 & 4 & & & 22,2 \\
\hline & & & 1 & 1 & 5,5 \\
\hline & & & & 1 & 2,7 \\
\hline & 5 & 5 & & & 27,7 \\
\hline & 1 & & & & 2,7 \\
\hline & & 2 & & & 5,5 \\
\hline & & & 4 & 4 & 22,2 \\
\hline & & & 3 & & 8,3 \\
\hline & & & & 1 & 2,7 \\
\hline Total & 10 & 11 & 8 & 7 & 100,0 \\
\hline
\end{tabular}


Foram vistos bilateralmente em 4 casos o ventre em posição cranial ao tendão $(22,2 \%)$, apenas à direita $(8,3 \%)$, e somente à esquerda em $(2,7 \%)$. Observamos o ventre do estilohióideo em posição ventral ao tendão intermediário bilateralmente $(27,7 \%)$, à direita $(2,7 \%)$ e no antímero esquerdo $(5,5 \%)$; a porção rostral do ventre caudal, bem como parte do tendão intermediário, se relacionaram rostroventralmente com parte da glândula submandibular e seu tecido conjuntivo de revestimento, bilateralmente $(83,3 \%)$, à direita $2 \operatorname{casos}(5,5 \%)$; o seguimento caudal do ventre acima referido relacionou-se com a glândula parótida ventralmente, bilateralmente $(33,3 \%)$; relacionou-se com linfonodos cervicais na face ventral do segmento caudal do ventre, bilateralmente $(11,1 \%)$ à esquerda $(5,5 \%)$; a artéria carótida externa próximo à sua bifurcação em artérias carótidas interna e externa relacionou-se com a porção intermediária do ventre caudal do músculo digástrico em sua face medial $(100 \%)$; foi possível observar relações bilaterais com o músculo esternocleidomastóideo que cobriu lateralmente o terço posterior do ventre caudal $(55,5 \%)$; observara-se relações com o músculo esplênio da cabeça, bilateralmente, nas quais o músculo cobriu uma pequena porção lateral da área de inserção óssea do ventre caudal na região do processo paracondilar $(22,2 \%)$.

\section{Discussão}

Ao discutir os resultados iremos compará-los com outros primatas, incluindo o ser humano, tecendo considerações, sobre a morfologia dos músculos supra-hióideos.

Os tratadistas referiram-se a dois ventres do músculo digástrico com tendão intermediário apoiado por fixação no osso hióide através da aponeurose que recobre o ventre posterior no ser humano ${ }^{11,12,13}$ ou recebendo reforços de fibras da fáscia cervical ${ }^{14}$ ou ainda preso por uma alça fibrosa $^{5,6,15}$. A afirmação de reforços na fixação do tendão intermediário por fibras das fáscias da região cervical confirmou-se neste trabalho no Cebus apella, de forma semelhante ao observado no homem pelos autores supra citados.

Percebemos que os ventres do músculo digástrico diferem quanto à forma, principalmente o rostral, conforme ilustrações, sendo este mais plano do que fusiforme semelhante o relatado no homem ${ }^{6,11,12,15,16}$. A similaridade de construção entre o músculo digástrico do Cebus apella e do homem naturalmente pode ser entendida em razão da proximidade evolutiva e do hábito alimentar destas espécies. No entanto, a abertura da boca pela ação dos dois ventres do músculo digástrico, derivado do primeiro e segundo arcos branquiais é uma característica dos mamíferos ${ }^{17}$. Com relação à inserção do ventre anterior na fossa digástrica, constatamos que esta apresentou-se bastante ampla partindo da linha mediana e expandindo-se caudolateralmente até o terço posterior do corpo da mandíbula, tendo o ventre muscular uma forma relativamente mais plana aproximando-se do apontado no Macaco rhesus em cebídeos e nos marmosets tem um ventre com duas camadas e o macaco uivador tem ventres triangulares, isto é, diferentemente do apontado no homem $^{5,14,18,19,20}$.

O assoalho da boca do ser humano foi descrito como uma espécie de maca formada pelos músculos milo-hióideo e digástrico ${ }^{21}$, tendo sido ainda comentado que o trígono submandibular é limitado pela margem inferior da mandíbula e os dois ventres do músculo digástrico ${ }^{16}$. Com relação a estes aspectos, neste primata pode-se afirmar que o músculo digástrico, exceto na linha mediana, formou um verdadeiro assoalho externo à cavidade bucal. Descrição aproximada foi feita em outros primatas, nos quais os ventres anteriores do músculo digástrico tem forma de leque, achatado enchendo o espaço triangular entre os dois ramos da mandíbula ${ }^{18}$. Topografia semelhante à encontrada neste estudo para 
o Cebus apella foi esquematizada para o Hylobates lar ${ }^{22}$ quando estes últimos autores trataram de atividades eletromiográficas dos músculos digástricos em gibão (Pongo pygmaeus) e orangotango (Hylobates lar). A inserção anterior na chamada fossa digástrica descrita no homem ${ }^{6,14}$ é muito mais expressiva neste macaco, e na maioria dos espécimes as fibras musculares avançaram sob a borda ventral da mandíbula, indo o ventre muscular até o terço médio do corpo mandibular, o que também ocorre no orangotango ${ }^{22}$. Com relação ao trígono submandibular, que é em parte ocupado pela glândula submandibular, pode-se afirmar que no Cebus apella em virtude do volume expressivo desta glândula, esta salta para fora deste espaço ${ }^{23}$ reforçado pelo alargamento retrocaudolateral do ventre rostral do músculo digástrico que juntamente com o músculo estilohióideo, estes se relacionam com a artéria submandibular oblíqua e posteriormente ${ }^{24}$. Pode-se considerar ainda que o ventre rostral do músculo digástrico do Cebus apella está diretamente relacionado ao aparelho hióideo por inserção aponeurótica, aspecto este igual ao apontado em chimpanzééc,25,26 e gibão e ao homem ${ }^{14,27}$.

Percebeu-se, em apenas 5,5\% dos casos estudados, a morfologia fusiforme do ventre rostral do músculo, tendo os outros 90,4\% características de ventres planos, prendendo- se ao osso hióide, através do tendão intermediário e estruturas conectivas expandido-se lateralmente e medialmente, através de reforços da fáscia cervical. Estes dados não estão referidos pela literatura nesta espécie.

Ainda em relação ao ventre cranial do músculo digástrico podemos confirmar que este no Cebus apella apresentou posição cranial em relação ao músculo platisma, estando situado antero-lateralmente à artéria e às veias faciais, à glândula submandibular e ao músculo masseter. Foi confirmada a relação caudal do ventre acima referido ${ }^{28} \mathrm{com}$ a artéria facial e a irrigação deste ventre, por ramos submentonianos e milo-hióideo da artéria facial ${ }^{8}$.
Com relação ao ventre caudal do músculo digástrico pode-se afirmar que este é fusiforme no Cebus apella, e semelhante à forma descrita nos Macaca mulatta, Alouatta vilosa e Cebus capucinus ${ }^{18}$. Originou-se no processo estilóide e manteve quatro diferentes tipos de relações com o músculo estilohióideo. Podendo estar este último sobre ou sob o seu ventre ou sob o tendão intermediário do músculo digástrico ou perfurando-o. No Alouatta seniculus, o músculo estilo-hióideo foi referido na borda superior do ventre superior do digástrico, separado pelo ramo principal do nervo facial, sendo envolvido e penetrado por traz e por baixo pelo tendão digástrico, onde suas fibras se inseriram, ou permaneceram medialmente até atingir o osso hióide ${ }^{29}$. No macaco rhesus o músculo estilo-hióideo é superior ao ventre posterior do músculo digástrico, podendo ter esta mesma relação em alguns marmosetts, sendo que nestes últimos o músculo não é perfurado pelo tendão intermediário e no Alonatta villosa o músculo estilo-hióideo é superior ao ventre posterior e ao tendão intermediário do músculo digástrico ${ }^{18}$. No Alouatta seniculus o tendão digástrico penetrou no músculo estilo-hióideo no sentido caudorostral $^{29}$, enquanto outros achados ${ }^{8}$ referem-se à presença da artéria carótida externa entre o músculo estilo-hióideo e o ventre caudal do digástrico. Já foi também referida no Macaco rhesus a relação do ventre caudal com a superfície profunda da glândula salivar submandibular ${ }^{7}$; com a artéria carótida externa lateralmente, com a artéria tireóidea superior ventralmente e com a artéria carótida interna medialmente ${ }^{8}$. No Cebus apella nossos resultados indicaram relações topográficas constantes do ventre caudal e tendão intermediário, com estruturas vasculonervosas do pescoço, além dos músculos estilo-hióideo, esternocleidomastoideo e esplênio da cabeça. Interessante salientar que relatos em Pongo pygmaeus ${ }^{30}$ referiram-se ao músculo digástrico com somente o ventre posterior, inserido no ângulo da mandíbula, homólogo ao ventre caudal por nós encontrado no Cebus apella. 


\section{Conclusões}

Com base nos resultados, podemos concluir que: o músculo digástrico é composto por dois ventres fusiformes, um rostral e um caudal, unidos por um tendão intermediário arredondado; o ventre rostral tem fibras que se dirigem rostro-caudalmente em relação ao tendão fusiforme e ao corpo do osso hióide; o ventre rostral do músculo digástrico relaciona-se ventralmente com o músculo hilo-hióideo, formando uma camada no assoalho da boca. O tendão intermediário em sua borda medial, no contorno do aparelho hióideo, faz uma curva e ancora-se na região média do corpo do osso hióide onde recebeu o reforço da aponeurose cervical. O ventre rostral relaciona-se com o músculo platisma, milo-hióideo, artéria e veia facial, glândula submandibular, músculo masseter, linfonodos submandibulares e osso hióide. $O$ ventre caudal do músculo digástrico origina-se no processo mastóide, próximo ao músculos esternocleidomastóideo e estilohióideo. A porção média de seu ventre, em sua face interna, relaciona-se com a artéria carótida externa e seus ramos temporais e occipitais; o nervo hipoglosso $(100 \%)$ passa medialmente à porção posterior do músculo. $O$ ventre caudal corre paralelamente ao músculo estilo-hióideo, podendo este cruzálo acima ou abaixo do tendão intermediário. $\mathrm{Nas}$ relações constantes deste ventre encontramos as seguintes estruturas: músculo estilo-hióideo, esternocleidomastóideo, esplênio da cabeça, nervo hipoglosso, feixe vásculo-nervoso do pescoço, glândula submandibular e glândula parótida.

\section{Agradecimentos}

À Prof ${ }^{a}$. Dr. ${ }^{a}$ Irvênia Luiza de Santis Prada que gentilmente nos cedeu os espécimes (acervo de pesquisa da Faculdade de Medicina Veterinária e Zootecnia da Universidade de São Paulo, Brasil) para a realização deste trabalho.

Apoio financeiro: FUNAPE Fundação de Apoio à Pesquisa, Universidade Federal de Goiás, Brasil.

\section{Study of muscle digastric descriptive and topographical anatomy in primates (Cebus apella, Linnaeus, 1766)}

\begin{abstract}
In this study we used 18 heads of monkey Cebus apella supplied by the Surgery Department of the School of Veterinary Medicine and Animal Science of the University of São Paulo. These heads were originally from the city of São Paulo Zoo of monkeys, who died naturally. The method included technique of light mesoscopy (40 magnifications), and the technical routine as follows: cannulation of the aorta toward the cranium; perfusion with water at $40{ }^{\circ} \mathrm{C}$; injection of the arterial system with stained latex solution (Neoprene 450 and Sulvinil stain), fixation and conservation in 10\% formol aqueous solution. Thirty-six antimeres were dissected. The digastric muscle, composed of two bellies (rostral and caudal) joined by an intermediate tendon, was inserted in the paramedian line of the mandible, from the incisive ventral border to the molar ventral border (rostral belly). The mode of origin, course and direction of the fibers showed three arrangements: one with plane bellies and fusiform tendon (55.5\%); one with plane belly, fibers inserted caudolaterally in the ventral mandibular border and fusiform tendon $(38.9 \%)$; and one with fusiform belly and tendon. The caudal belly was related to the belly and tendon of the stylo-hyoid muscle,
\end{abstract}

Key-words: Digastric muscle. Cebus apella. Rostral belly. Caudal belly. 
crossing it ventrally $(22.2 \%)$ or dorsally (2.7\%); crossing the intermediate tendon ventrally $(35.9 \%)$ or dorsally $(33.2 \%)$. The digastric muscle (rostral belly) is plane in Cebus apella (94.4\%), has a wide bone insertion, in the ventral mandibular border and the intermediate tendon rests on the cervical fascia, in lateral expansion until it reaches the bone, thus making up a double supporting point $(38.9 \%)$.

\section{Referências}

1 FUTUYMA, D. J. Biologia evolutiva. 2. ed. Ribeirão Preto: Soc. Bras. De Genética / CNPq, 1993. p. 233239.

2 BROWN; COLILLAS. Ecologia de Cebus apella. Distribuicion y simpatia de las espécies del Gênero Cebus. In: PRIMATOLOGIA NO BRASIL, Anais... 1983, Belo Horizonte, p. 306.

3 VALLS, A. Introduccion a la antropologia. Fundamentos de la evolucion y la variabilidade biológica del hombre. 2. ed. Barcelona: Labor Universitárias, 1985 p. 302-306, 560-562.

4 WARWICK, R.; WILLIAMS, P. L. Gray anatomia. 35. ed. Rio de Janeiro. Guanabara Koogan, 1979. p. 600605.

5 GOSLING, J. A.; HARRIS, P. F.; HUMPHERSON, J. R.; WHITMORE, I.; WILLAN, P. L. T. Anatomia humana: atlas colorido e livro-texto. 2. ed. São Paulo: Manole, 1992. pranchas $7.12 ; 7.24 ; 7.25 ; 7.26$.

6 JOHNSON, D. R.; MOORE, W. J. Anatomia para estudantes de odontologia. 3. ed. São Paulo: Guanabara Koogan, 1997. p. 154.

7 GEIST, F. D. Nasal cavity, larynx, mouth and pharynx. In: LINEBAK, P. The anatomy of the rhesus monkey (macaca mulatta). New York: Hafner, 1961. Cap. 9, p. 189-209.

8 CASTELLI, W. A.; HUELKE, D. F. The arterial system of the head and neck of the rhesus monkey with emphasis on the external carotid system. American Journal of Anatomy. v. 116, n. 1, p. 149-170, 1964.

9 INTERNATIONAL COMMITTEE ON VETERINARY GROSS ANATOMICAL NOMENCLATURE. Nômina anatômica veterinária. 4. ed. Zurich, 1994.

10 SCHALLER, O. Nomenclatura anatômica veterinária ilustrada. São Paulo: Manole. 1999. p. 38-39, 102-103.

11 LLORCA, F. O. Anatomia humana. Barcelona: Editorial Científico Médica. 1952. tomo 3, p. 382-383.

12 ROUVIÉRE, H. Anatomia humana descriptiva y topográfica. $5^{\text {a }}$ ed. Madrid: Editorial Bailly-Bailliere, 1959. tomo 1, p. 156-157.

13 TESTUT, L.; JACOB, O.; BILLET, H. Précis-atlas de dissection des regions. Paris: Octave Doin, 1921. p. 65.

14 MADEIRA, M. C. Anatomia da face: bases anátomo funcionais para a prática odontológica. 3. ed. São Paulo: Sarvier, 2001. p. 88.

15 FERNER, H.; STAUBESAND, J. Sobotta. Atlas de anatomia humana. 18. ed. Rio de Janeiro: Guanabara Koogan. 1984. p. 182-196.

16 DANGELO, J. G; FATTINI, C. A. Anatomia humana sistêmica e segmentar: para o estudante de medicina. 2 . ed. Rio de Janeiro: Atheneu, 1988. p. 671.

17 HILDEBRAND, M. Músculos e órgãos elétricos. In: Análise da estrutura dos vertebrados. São Paulo. Atheneu, 1995. p. 209-210.

18 HILLOOWALA, R. A. Comparative anatomical study of the hyoid apparatus in selected primates. American Journal Anatomical, v. 142, p. 367-384, 1975.

19 MACMINN, R. M. H.; HUTCHINGS R. T.; PEGINGTON, J.; ABRAHAN P. H. Atlas colorido de anatomia Humana. 3. ed. São Paulo: Manole, 1997. p. 47-47.

20 ROHEN, J. W.; YOKOCHI, C. Color atlas of anatomy: a photografic study of the human body. 3rd. edition. New York: Medical Publishers,1993. p. 152-153, 162, 165.

21 LOCKHART, R. D.; HAMILTON, G. F.; FYFE, F. W. Anatomia do corpo humano. 2. ed. Rio de Janeiro: Guanabara Koogan, 1983. p. 734-735.

22 WALL, C. E.; LARSON, S. G.; STERN, J. T. EMG of the digastric muscle in gibbon and orangutan: fucntional consequences of the loss of the anterior digastric in orangutans. American Journal of Physical Antrophology, v. 94, p. 549-567, 1994.

23 BLUMENSCHEiN, A. R; FERREIRA, J. R. Anatomic study of the neotropic primate's submandibular gland ducts (Cebus apella, Linnaeus 1766). Rev. Chil. Anat., v. 20, n. 1, p. 55-61, 2002.

24 OLIVEIRA, A. S.; FERREIRA, J. R.; BLUMENSCHEIN, A. R. Estudo anatômico do modelo arterial de vasos responsáveis pelo aporte sangüíneo da glândula submandibular de primatas neotropicais (Cebus apella, Linnaeus, 1766). Acta Scientiarum, v. 22, n. 2, p. 573579,2000 .

25 RAVEN, H. C. The anatomy of the gorilla. New York: Columbia University Press, 1950.

26 SONNTAG, C. F. On the anatomy, physiology, and pathology of the chimpanzee. Proc. Zool. Soc. Lond., p. 
323-429. 1923.

27 MUNRO, R. R. Structure and functions of the digastric muscle. J. Anat., v. 144, p. 146, 1973.

28 MADEIRA, M. C.; WATANABE, II-S. Dados anatômicos sobre a artéria facial no homem (fetos e adultos) e no macaco prego (Cebus apella). Rev. Fac. Odont., Araçatuba, v. 7, n. 1, p. 59-67, 1978.

29 SCHÖN, M. A. Posible function of some pharyngeal and lingual muscles of the howling monkey (Alouatta seniculus). Acta anat., v. 58, p. 271-283, 1964.

30 WINKLER, L. A. Morphology and variability of masticatory structures in the orangutan. International Journal of Primatology, v. 12, n. 1, p. 45-65, 1991.

31 ANDREO, J. C; PAI, V. D; NAVARRO, J. A. C; DE OLIVEIRA, J. A. Fiber types in the digastric muscle of tufted capuchin monkey (Cebus apella). Anat. Histol. Embryol.v. 23, n. 3, p. 226-231, 1994. 